\title{
Quiet Participation: Investigating Non-Posting Activities in Online Learning
}

\author{
Lesley Wilton \\ University of Toronto
}

\begin{abstract}
Despite the growth in online learning offerings in K-12 and higher education, limited research has been undertaken to better understand less visible online learning activities. Reading and rereading are not typically valued as important indicators of learning since the number or frequency of entries, words, or key phrases are usually visible and easily tracked. This article reports on a mixedmethods study addressing the reading, writing, and revisiting activities of graduate students attending one of eight online graduate courses taking place over a four-year period. Students were grouped by clusters of reading and writing activities to identify patterns related to rereading. Participant perceptions of the value of rereading entries in online learning are discussed. The findings highlight the importance of a more nuanced understanding of the different roles reading and rereading play in online learning discussions. This research informs our understanding of the importance of non-posting behaviors to student learning. Instructionally, these results may encourage the valuing of different "paths" to online learning success beyond the criterion of written entries.
\end{abstract}

Keywords: online learning discussions, rereading, revisiting, non-posting participation, DBOLE, quiet participation

Wilton, L. (2018). Quiet participation: Investigating non-posting activities in online learning. Online Learning, 22(4), 65-88. doi:10.24059/olj.v22i4.1518

\section{Quiet Participation: Investigating Non-Posting Activities in Online Learning}

As participation in formal online learning communities continues to grow in K-12 schools (Barbour \& LaBonte, 2017), and in post-secondary settings (Johnson et al., 2014; Means, Toyama, Murphy, Bakia, \& Jones, 2010), contextualized explorations of practices central to learning in discussion-based online learning environments (hereafter referred to as DBOLEs) are important to conduct. Research examining interactions through posted texts is contributing to our understanding of the relationship between reading and writing in online discussions (Bonk \& Cunningham, 1998; Harasim, 2012; Wise, Hausknecht, \& Zhao, 2013a). Studies in this area typically place greater emphasis on the more visible written contributions and are often positivist and quantitative (Picciano, 2016). Furthermore, instructional designers are seeking to engage silent learners 
(Creelman, 2017), but it may be that such learners learn best through quiet participation activities such as reading and rereading.

Researchers Wise, Perera, Hsiao, Speer, and Marbouti (2012) conducted microanalytic case studies of three students' interaction patterns, intended to advance "a new microanalytic approach for making sense of the detailed log-file data available from online discussions" (p. 109), to provide insight into individual online activities. The authors looked at the ways non-posting behaviors influenced learning. This is instructionally important because engagement is often inferred by observing the frequency of posting activities. Students who are new to learning through online discussions, or who are experienced in online discussions that do not value online postings, may adopt different participation patterns than those expected by instructors who value visible participation (Dennen, 2006). Looking at revisiting patterns (returning to previously read entries to reread part or all of the text) may also be helpful as indicators of areas of difficulty or student interest. As multiple scholars call for empirical research on student behaviors in asynchronous learning discussions (Harasim, 2012; Ho \& Swan, 2007; Peters \& Hewitt, 2010), a deeper understanding of these non-posting patterns may provide instructors with insights into more comprehensive interpretations of patterns of engagement and understanding (Wise, Speer, Marbouti, \& Hsiao, 2013b).

As an online learning instructor who has attended online courses as a student, my interest in better understanding meaningful, less-visible online discussion activities developed while observing learners who participated by posting discussion entries less frequently than others. It is important to consider measures of learning in online discussion environments that better account for diversity, whether culturally or experientially-based. Research examining the less visible practices of reading and rereading in online learning environments is needed to contribute a deeper understanding of the importance of these activities to learning.

What follows this introduction is the literature review, research method, results, discussion, and conclusion and implications related to a portion of a larger study of 137 online learning graduate students' attending one of eight fully online classes over a four-year period. The portion

of the study forming the basis of this article looks at patterns and perceptions of less visible online learning activities in eight DBOLEs to gain a deeper understanding of the role of reading, rereading, and revisiting activities.

\section{Review of Related Literature}

Students who write less in DBOLEs may inaccurately appear to others to be less engaged. Entries that are visible to others (i.e. students and instructors) are typically valued as evidence of learning (Rourke \& Kanuka, 2009; Swan, Shen, \& Hiltz, 2006). It is generally assumed that composing an entry in an online learning discussion is preceded by reading other entries. Yet, despite the amount of time required to read and process others' entries, reading of those entries in discussions is itself not generally valued or studied (Hrastinski, 2008; Wise et al., 2013b). While reading and rereading activities may be difficult to fully measure, is it fair to students - who find these practices to be meaningful to their learning - to ignore the significance or importance of these activities? Should we not, instead, recognize practices in online learning that contribute to student learning and require an investment of time and effort, but may not be as visible to others as entries that are posted? 
Some studies that look at patterns of posting and responding recognize reading activities, but negatively characterize those who write less (i.e. those who are less visible) as lurkers (Perkins \& Newman, 1996) or as silent participants (Nonnecke \& Preece, 2003). A theory of vicarious interaction is proposed by Sutton (2001) when looking at activities taking place in distance education classrooms. She observes that students who do not visibly interact with others by posting many entries are still able to achieve learning benefits from reading what others have written. However, Rovai (2000) proposes that visibility in a DBOLE is important to community and student interaction. Important to note is that the literature reports that those who post less may be more likely to receive a lower grade. Nagel, Blignaut, and Cronjé (2009), who found a relationship between visible contributions and course grades in their small study involving 22 students, concluded that read-only participation should be avoided. On the other hand, Ebner and Holzinger (2005), observed that visible interactions do not necessarily indicate learning. It would seem that students participate in online classrooms in a variety of quiet ways that are not deeply understood.

Creelman (2017) recently edited a paper on behalf of the Nordic Council of Ministers, which was prepared as a guide for instructors on how to engage silent learners and be more inclusive by offering "alternative pathways for learners and ensur[ing] that different competences and learning strategies are recognized" (p. 26). The paper describes a variety of reasons some learners are silent in online courses. A selection of these proposed reasons includes the following:

- Prefer to work alone without disturbance; a genuine introvert.

- Unclear about how to be active in an online course - unfamiliar with the 'rules' or etiquette of participation. Waiting for a cue to participate.

- Need more time to think before contributing.

- Feel overwhelmed and ignored by the extrovert members of the group. Hard to make yourself heard.

- Shy and nervous about participation in general.

- Low confidence - any setback can confirm feeling of inadequacy.

- Due to perceived language difficulties.

- Cultural reasons - not polite to question the teacher or start talking without permission (p. 12-13).

In looking at the literacy processes involved in online learning classroom conversations, Vogler et al. (2013) concluded that even though their participants were engaged in the same online learning conversation, their experiences varied considerably. The authors examined the literacy processes of reading and rereading and identified three distinct patterns of behaviors. One of these patterns featured reading, revisiting, and the careful crafting of discussion responses. It is not clear if instructors would recognize the value of these less visible practices to student learning. Other important elements of course discussions examined by Dennen and Wieland (2007) include social acknowledgements, questions, and the processes involved in interactive discussions, but these are mainly visible components.

Some researchers seek to better understand the relationship between reading and writing in online learning discussions. Categorizing these activities as listening and speaking, Wise et al. (2013a) looked at listening behaviors to identify a pattern of revisiting where "students can choose to return to posts (made by themselves and others) that they have attended to previously" (p. 2). Their study, which examined the interactions of 31 undergraduate students, identified a positive relationship between revisiting other students' entries and the quality of responses. The authors call for more in-depth research on the less visible activities of reading and revisiting. 
Applying a social literacies lens when looking at reading and writing in online classroom environments, Goodfellow (2004) argues for more research to better understand the "social-andcultural domain of online literacies" (p. 397). He refers to those who read more and write less than others as passive participants, though this term also seems to undermine the time and effort required to participate in less visible ways. While there is much published research on the practices involved in reading and writing in a face-to-face classroom, there is a gap in understanding the less visible social practices of online classroom interactions.

Guiding this research is an understanding of the Sociocultural Theoretical (SCT) perspectives that learning with others through social interaction is essential to individual knowledge construction (Lave \& Wenger, 1991; Vygotsky, 1986). The concept of the Zone of Proximal Development (ZPD) from SCT perspectives is important to learning in a DBOLE. JohnSteiner and Souberman (1978) quote Vygotsky's Thought and Language (1934) to explain the ZPD as "the distance between the [student's] actual development level as determined by independent problem solving and the level of potential development as determined through problem solving under adult guidance or in collaboration with more capable peers" (p. 131). In the case of an online classroom, the ZPD could be supported by students reading or rereading other students' entries and possibly by intertwining the revisiting of their own entries while reading others' thoughts and ideas. John-Steiner and Souberman (1978) explain how Vygotsky emphasized the importance of dialogue to learning since the "mere exposure of students to new materials through oral lectures neither allows for adult guidance nor for collaboration with peers" (p. 131). Online student discourse involves posting opinions and commentary on relevant topics for others to read and discuss (Harasim, 2012). Perkins and Newman (1996) viewed online discussion or e-discourse as a new way of writing, which is not speaking or letter-writing; Hrastinski (2009) argued that online learner participation is "not synonymous with talking or writing" (p. 78). Online dialogues are also very influenced by instructor models (Dennen, 2006).

Typically, the visibly posted contributions are assessed, often worth $5 \%$ to $25 \%$ of the course's grade, according to their number, frequency, and length (Rourke \& Kanuka, 2009; Swan et al., 2006). However, there is a concern about valuing superficial posts. Some caution that learning may not be fully evidenced in students' written entries, and that some students may simply be meeting suggested criteria (Dennen, 2008; Ho \& Swan, 2007). On the other hand, Yang and Richardson (2008), in a small exploratory study of interaction styles, looked at learner activities and suggested that it is most likely there will be some vicarious learners in any online class. They cautioned that online instructors should be aware of students who may prefer observation rather than visibly contributing, and that "using traditional assessment of online discussions, such as simply counting the number of postings, may be a disadvantage for them" (p. 8).

Further, we know little about learners who post smaller numbers of course entries, but who still receive passing grades or who perceive their learning to be successful. It has been acknowledged, "passive participation may still be a legitimate contribution to online discussion" (Goodfellow, 2004, p. 392). However, earlier research of students who read many entries but wrote less, suggests that reading is an important component of online learning and may help learners achieve a deeper understanding of complex subject matter (Wilton \& Brett, 2015).

Another perspective that could add to a deeper understanding of reading, rereading, and revisiting in online learning is the perspective of these activities as less visible social practices. Emerging research using a new literacies paradigm reports on social practices in the context of fan fiction, blogging, online social networking, and others (Knobel \& Lankshear, 2015). However, 
there is a gap in the study of literacy and social practices in formal online learning environments (Knobel, 2015). Lankshear and Knobel (2007), whose new literacies research looks at emergent forms of literary practices, argue that sociocultural definitions of literacies must make sense of "reading, writing, and meaning-making as integral elements of social practices" (p. 2). The authors explain that online text-mediated practices led to emergent social practices, such as weblogging (Lankshear \& Knobel, 2004, p. 1). They call for rich accounts of these social practices to inform teachers' and educators' understandings of their importance.

Another consideration is that an activity such as rereading is not one that is available to students participating in a face-to-face classroom discussion. Viewing these activities as social practices can potentially highlight the importance of such activities as facilitating an online discussion, questioning to generate discussion, restating in different words, and clarifying in digital form, whether occurring asynchronously or synchronously.

Finally, an interpretive perspective guides this research by providing a framework that focuses on "understanding and meaning-making as opposed to explanation" (Bhattacharya, 2008, p. 464). The interpretive framework supports the view that such understandings are particular to "each knower/observer according to a set of subjective principles peculiar to that person" (Sipe \& Constable, 1996, p. 158). This interpretive view serves to inform an understanding of the quiet practices taking place in online learning discussion environments by emphasizing the importance of deeper descriptions of the context and the perspectives of the participants and the researcher.

These lenses guide the examination of less visible practices in eight DBOLEs and their relationships to student learning through the key research objectives of this portion of the study:

1. To document learners' patterns of reading and writing behaviors in a discussion-based online learning environment.

2. To document learners' patterns of revisiting behaviors in a discussion-based online learning environment.

3. To investigate learner perceptions of their non-posting activities (reading and revisiting) and how they see these activities as important to their learning experiences.

\section{Context and Participants}

\section{Methods}

Researchers studying online and blended learning environments are increasingly adopting a mix of quantitative and qualitative methodologies within the interpretive perspective (Picciano, 2016). A mixed methods design (Creswell \& Plano Clark, 2011) was used to investigate the online activities of 137 participants who attended eight fully online 12-week graduate courses in the Faculty of Education of a large Canadian university. The study took place over four years in a collaborative conferencing environment developed in-house, where quantitative data of online entries and activities, including creating, opening, and revising entries were automatically collected.

The conferencing program features included public and private discussion threads, private and group messaging, and liking and linking to other entries. The same experienced instructor taught all courses. Students were required to provide an introductory entry, to update a public learning journal regularly, and to participate in weekly online discussions facilitated by different class members. In these courses, participation was worth $25 \%$ of the overall course grade. To that 
end, the instructor did not prescribe a set number of entries or words, but rather asked for entries that reflected evidence of deep engagement with the course materials or discussion.

Figure 1 shows a sample of the DBOLE interface for one of the courses included in the study.

\begin{tabular}{|l|l|l|l|l|l||l|l|}
\hline Home & Community & Messages (2) & Preferences & Administration & Windows $\boldsymbol{\nabla}$ & Lounge & Logout \\
\hline
\end{tabular}

\section{Home}

$\square$ Start Here!
$\square$ Course Administration
$\square$ Announcements
$\square$ Technical Questions and Course Help
$\square$ Class Biographies
$\square$ Class Cafe
$\square$ Practice
$\square$ Useful Readings and References
$\square$ Learning Journals
$\square$ Class Theories of Learning and Technology.
$\square$ Week 1 - Introduction and Overview
$\square$ Week 2 - History of Constructivism Part 1
$\square$ Week 3 - History of Constructivism Part 2
$\square$ Week 4 - Social and Cultural Influences
$\square$ Week 5 - Situated Learning Part 1
$\square$ Week 6 - Situated Learning Part 2

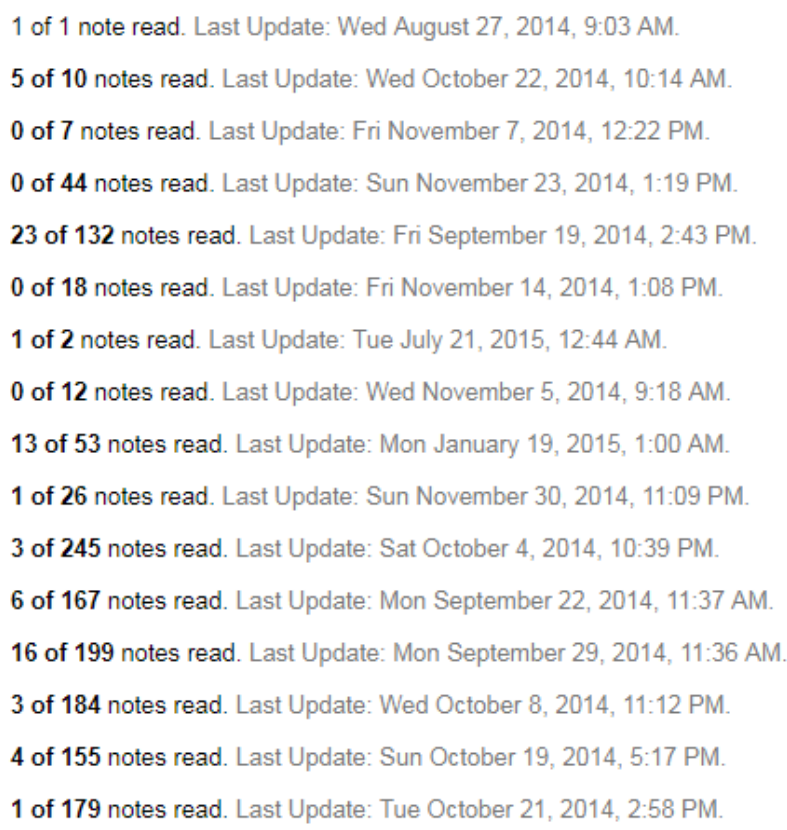

Figure 1. Example of the DBOLE interface

\section{Data Collection}

In addition to the log data automatically collected by the conferencing system on the activities of the 137 participants, data was collected from a convenience sample (Creswell, 2013) of 14 volunteer participants through an online questionnaire that was estimated to take about 15 minutes to complete. The survey was designed to gather students' perceptions of their online learning experiences, including reading and rereading activities. See Appendix A for the instrument used to collect this data as part of a larger study (Wilton, 2017). Four student participants further volunteered for semi-structured interviews designed to more deeply discuss student perceptions of reading and rereading in a DBOLE. See Appendix B for an outline of the semi-structured interview questions. Interviews were recorded using multiple digital sources to avoid any possibility of data loss and were transcribed verbatim. One participant chose to respond by email. Within the interpretive paradigm, qualitative data provides sense making (Bhattacharya, 2008) and can identify variables that are difficult to measure (Creswell, 2013). 


\section{Data Analysis}

Descriptive statistics were produced using SPSS (a statistical software package), Version 24 , to allow for an overview of course activities. Figure 2 illustrates the number of students and number of written entries, representing visible activities in the course. Each course is identified as DB 1 to 8.

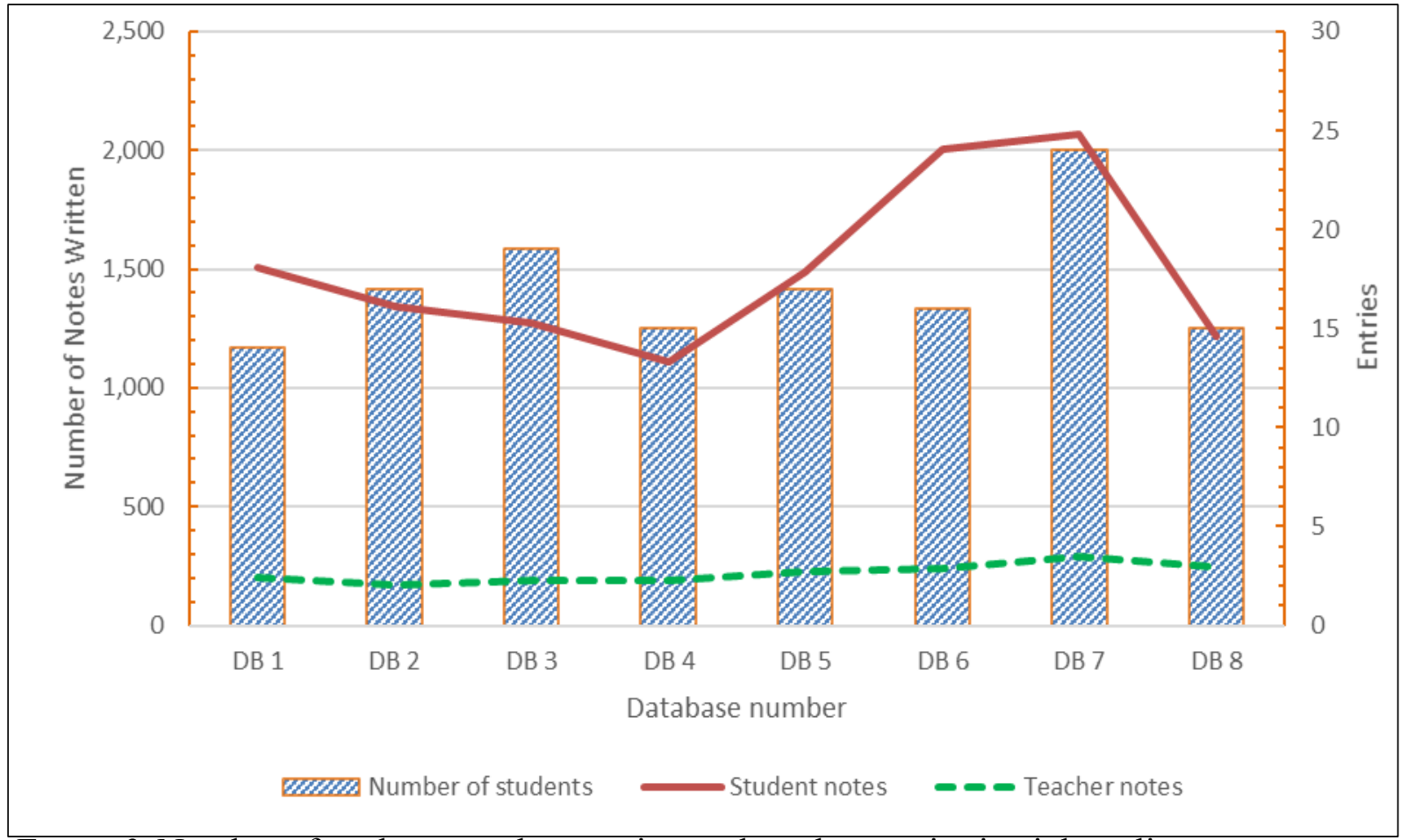

Figure 2. Number of students, student entries, and teacher entries in eight online courses.

Participant activities related to 13,754 entries were turned into percentages within each course. SPSS performed non-model-based cluster analysis identifying group patterns of reading and writing (Green \& Salkind, 2011). For all 137 cases, participants were clustered into three reading/writing behavior categories, with a reported good quality silhouette measure of cohesion and separation (0.6) (see Table 1$)$.

Table 1

\section{Cluster Membership}

\begin{tabular}{lcccc}
\hline Cluster & $\begin{array}{c}\text { Number } \\
\text { of } \\
\text { students }\end{array}$ & $\begin{array}{c}\text { Range of \% } \\
\text { of student } \\
\text { entries read } \\
(\mathrm{M})\end{array}$ & $\begin{array}{c}\text { Range of \% } \\
\text { of student } \\
\text { entries } \\
\text { written (M) }\end{array}$ & $\begin{array}{c}\text { Range of } \\
\begin{array}{c}\text { \# of } \\
\text { entries } \\
\text { written }\end{array}\end{array}$ \\
\hline 1 Avid Readers/Prolific Writers & 31 & $42-100(85)$ & $7-16(10)$ & $87-286$ \\
2 Avid Readers/ Moderate Writers & 40 & $63-99(83)$ & $2-7(5)$ & $24-145$ \\
3 Moderate Readers/ Moderate Writers & 66 & $11-62(41)$ & $1-9(4)$ & $17-145$ \\
\hline
\end{tabular}


Named according to the levels of reading and writing activities represented, these three clusters are not intended to cleanly divide student groups, but to identify general groups according to these behaviors. Figure 3 illustrates the cluster groupings.

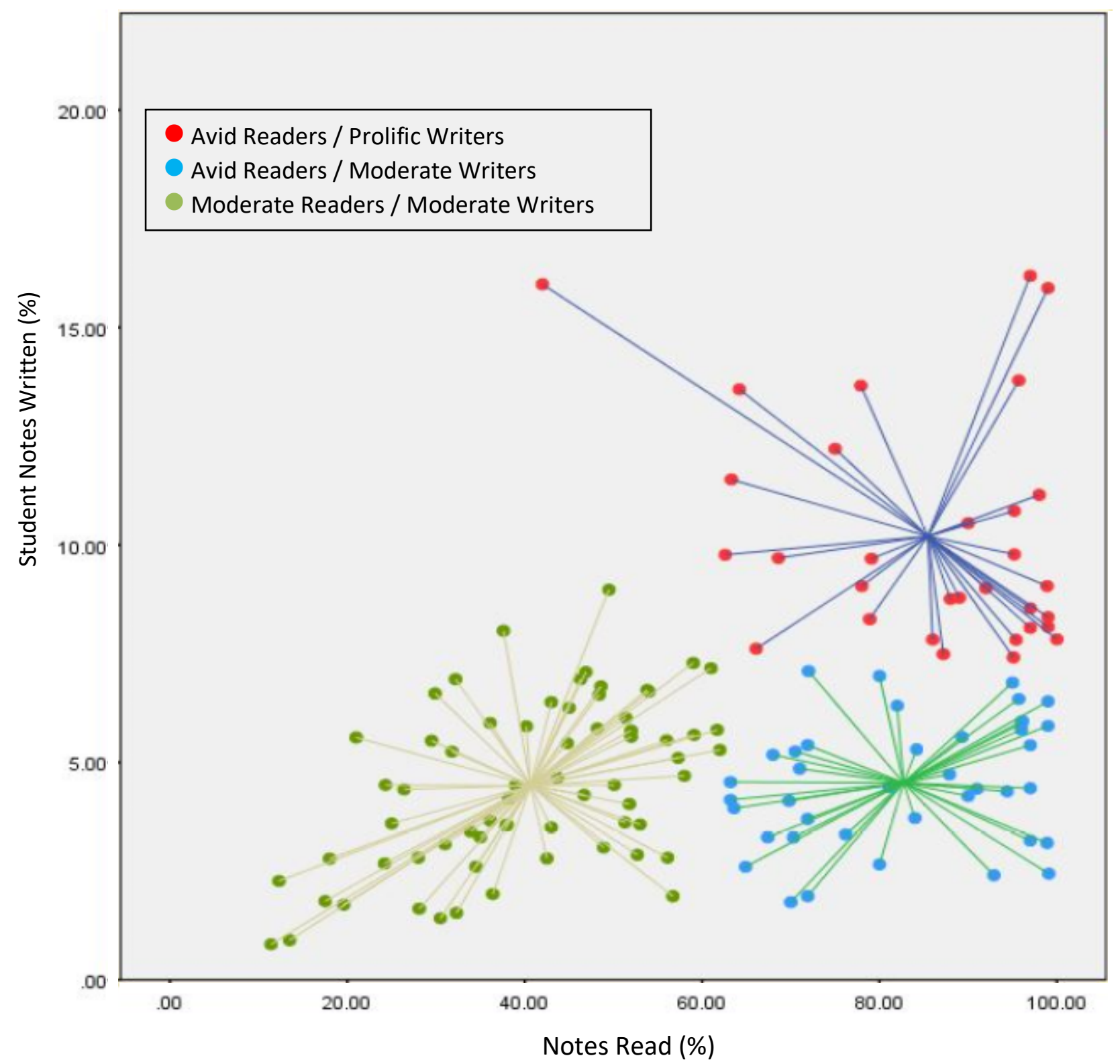

Figure 3. Scatterplot of cluster membership

The 14 participants who participated in the online survey were assigned pseudonyms. Transcripts of the opened-ended responses and the interviews were analyzed using an ad hoc meaning generation method (Kvale, 2007) for themes related to the importance of reading and rereading activities. The study involved multiple sources of evidence and was designed to carefully consider credibility, transferability, dependability, and confirmability. The results of the survey data were triangulated with $\log$ file and interview data. 
The four principles of data collection (Yin, 2014) were engaged to address the standards of validation and evaluation as well as trustworthiness and reliability. Yin (2014) described these principals as 1) using multiple sources of evidence, 2) creating a database of evidence, 3) maintaining a chain of evidence and 4) using electronic evidence with care. Multiple sources of evidence related to log-file data, interviews, observations, and artifacts of entries were gathered to create a comprehensive collection of data.

Illustrative data from only two of these participants who participated in three of the eight courses are presented in this paper to provide an in-depth view of the data and in consideration of space limitations. One participant was assigned to the Moderate Reader/Moderate Writer cluster group and the other participant was assigned to the Avid Readers/Prolific Writers cluster group.

\section{Results}

Looking at the identified clusters by student reading and writing activities, Table 1 shows that the students classified as Avid Readers (Clusters 1 and 2) tended to open many entries at least once, and the Prolific Writers (Cluster 1) typically wrote more entries than others. The Avid Readers/Prolific Writers wrote between $7 \%$ and $16 \%$ of the entries in the discussions. They read between $42 \%$ and $100 \%$ of the entries in the discussions. There were 31 students in this category. The Avid Readers/Moderate Writers were less visible, writing between $2 \%$ and $7 \%$ of the entries in the discussions. They read between $63 \%$ and $99 \%$ of the entries in the discussions. There were 40 students in this category. The other category of students who were less visible is the Moderate Readers/Moderate Writers. These students wrote between $1 \%$ and $9 \%$ of the entries in the discussions. They read between $11 \%$ and $62 \%$ of the entries in the discussions. There were 66 students in this category.

\section{Importance of Reading-Related Practices}

The 14 volunteer online survey respondents were asked to rate-using a 5-point Likert scale - the importance of a variety of activities related to reading and rereading. Revisiting students' entries to improve my understanding was reported as important by all 14 participants. All four Avid Readers/Prolific Writers and all seven Moderate Readers/Moderate Writers indicated that composing an entry with an opinion that has not been expressed by others and composing an entry that refers to another student's entry were most important, in contrast to the three Avid Readers/Moderate Writers who felt that composing an entry that refers to another student's entry was neither important nor unimportant. In addition to log file data confirming that revisiting other students' entries was taking place, the online survey participants confirmed that revisiting other students' entries was important to improve understanding in the course.

\section{Less Visible Practices: Revisiting}

To better understand the importance of revisiting, the online survey participants were asked why they might revisit an entry in the course. A series of questions was presented as "select all that apply." The majority (12 out of 14) felt that revisiting entries added a perspective on something I was having difficulty with and it was helpful to my learning. Social pressure to "fit in" was the least frequently selected reason. Notably, a less visible participant classified as an Avid Reader/Moderate Writer (\#6) felt revisiting entries was socially driven, though this reason was not selected by any of the Moderate Readers/Moderate Writers. The responses illustrated that 
revisiting other students' entries may support learning through a type of ZPD process, where revisiting a peer's articulation of a concept could support deeper understanding.

\section{Less Visible Practices: Reasons for Rereading}

To better understand the 14 respondents' perceptions of why revisiting may be an important practice, participants were asked why they would revisit/reread previously read entries (OpenEnded Online Survey Interview Question 9). Four themes were identified: to deepen understanding, for clarification, to support a socially correct action and because it contained a helpful resource. Table 2 shows selected comments to illustrate the themes.

Table 2

Themes Expressed to Deepen Understanding

Theme

To Deepen

Understanding

Socially Correct

Contained a

Useful Resource Clarification
Example

- To review relevant and important ideas that helped with my understanding of the content. (Participant \#3)

- Once I gained a better understanding of a topic, I reread other people's posts to better appreciate their post or point of view. (Participant \#10)

- I believe revisiting students' entries helps to reinforce concepts read about and discussed. It adds different perspectives and changes my overall outlook, which in turn gives me a broader toolkit from which to choose. (Participant \#1)

- I tried to get a better understanding of what the students meant. In For many cases it was after reading other comments or thinking about

Online learning facilitates revisiting for better understanding and clarification because of the permanence of the discussions. Some respondents noted that revisiting was important before responding, to avoid repeating something that had already been said or to correctly cite something in a quote. The data may be indicative of participation styles, similar to those highlighted by Creelman (2017). The survey data also indicates that social factors were important to some.

\section{Types of Student-Generated Entries Likely to be Revisited}

Four themes were identified when students were asked to describe the student-generated entries most likely to be reread (Open-Ended Online Interview Question 11 from the survey): entries that contributed to understanding, that were provoking, that included a personal connection, or that contained helpful resources. Table 4 shows selected comments to illustrate the themes highlighted as types of entries likely to be revisited. 
Table 3

Types of Student-Generated Entries Likely to be Revisited

\begin{tabular}{|c|c|}
\hline Type of Entry & Example \\
\hline $\begin{array}{l}\text { Entries That } \\
\text { Contributed to } \\
\text { Understanding } \\
\text { (well-written) }\end{array}$ & $\begin{array}{l}\text { - Well thought-out entries. Well-composed entries. Entries with } \\
\text { excellent connections to the research. (Participant \#3) } \\
\text { - Entries that made me think. (Participant \#4) } \\
\text { - Entries that are insightful and show a deeper understanding of the } \\
\text { topic. (Participant \#5) } \\
\text { - Posts from students I have identified as "getting it" and therefore good } \\
\text { role models; Anything I'm responding to. (Participant \#13) }\end{array}$ \\
\hline $\begin{array}{l}\text { Entries That Were } \\
\text { Provoking }\end{array}$ & $\begin{array}{l}\text { - Opinions I don't understand or agree with, and after rereading my } \\
\text { readings and then going back to the posting. (Participant \#9) }\end{array}$ \\
\hline $\begin{array}{l}\text { Personal } \\
\text { Connection }\end{array}$ & $\begin{array}{l}\text { - Explaining a difficult concept from course materials by using real- } \\
\text { world examples, often from the person's own experience, or one that } \\
\text { simplifies concepts by using more novice-friendly language. } \\
\text { (Participant \#10) }\end{array}$ \\
\hline $\begin{array}{l}\text { Entries Containing } \\
\text { Helpful Resources }\end{array}$ & - Helpful entries with useful resources. (Participant \#3) \\
\hline
\end{tabular}

Clarifying, building on understanding, and ensuring a socially correct response were highly identified by the 14 participants as important reasons for revisiting in a DBOLE. The types of entries participants preferred to revisit were well written, insightful, clarifying, summarizing, provoking, questioning, or contained resources. Entries that contained personal examples were also preferred. Social factors also appeared to be important influences for revisiting.

\section{Less Visible Practices: Differences in Revisiting Behaviors}

Table 4 illustrates the average number of hours online and the revisiting activities by cluster groupings, related to student entries and teacher entries.

Table 4

Revisiting Activity Clusters in Relation to Hours Online

Entry revisits by type

\begin{tabular}{|c|c|c|c|}
\hline Cluster & $\begin{array}{c}\% \text { of total } \\
\text { student entries } \\
\mathrm{M}(\mathrm{Min})(\mathrm{Max})\end{array}$ & $\begin{array}{c}\% \text { of total teacher } \\
\text { entries } \\
\text { M (Min) (Max) }\end{array}$ & $\begin{array}{l}\text { Hours online } \\
\text { M (SD) }\end{array}$ \\
\hline 1 Avid Readers/Prolific Writers & $30.7^{1} 10.778 .4$ & $45.7^{1,2} 23.879 .8$ & $89^{1}(31)$ \\
\hline 2 Avid Readers/Moderate Writers & 8.144 .1 & $36.3^{1} \quad 20.6 \quad 55.1$ & $73^{1}(31)$ \\
\hline $\begin{array}{l}3 \text { Moderate Readers/Moderate } \\
\text { Writers }\end{array}$ & 2.525 .5 & 8.448 .4 & $47 \quad(21)$ \\
\hline
\end{tabular}


Since Levene's Test of Homogeneity reported that the data represented in Table 4 violated the assumption of equal variances, the Dunnet-C post hoc test, which is tolerant of the lack of homogeneity of variance among the dependent variables, identified a significant difference in several of the means. Those belonging to the group of Moderate Readers/Moderate Writers spent significantly fewer hours online, on average, $(M=47)$ than the Avid Readers/Prolific Writers $(M$ = 89) or the Avid Readers/Moderate Writers $(\mathrm{M}=73)$. Further, this data shows that Moderate Readers/Moderate Writers, on average, reread significantly fewer student and teacher entries than the other cluster groupings.

Of note, the ratio of student entries reread to teacher entries reread for Moderate Readers/Moderate Writers is higher at 1:2.2 compared to 1:1.6 for the Avid Readers/Moderate Writers, and 1:1.5 for the Avid Readers/Prolific Writers. These data show that the Moderate Readers/Moderate Writers tend to read more teacher entries in proportion to other student entries.

\section{Less Visible Practices: Revisiting In-Depth}

Select interview findings from Samira, a Moderate Reader/ Moderate Writer who is new to online learning, and Trisha, an Avid Reader/Prolific Writer, who is very experienced in online learning, and is an online teacher, are included to illustrate data supporting a more nuanced understanding of participant perceptions. The data related to Samira's and Trisha's activities were gathered from three different courses with a total of 56 participants. Trisha attended two courses and Samira attended one.

Table 5

Sample activity of two students' activities

\begin{tabular}{lcc|cc|cc} 
& \multicolumn{2}{c}{ Samira in Course \#3 } & \multicolumn{2}{c}{ Trisha in Course \#5 } & \multicolumn{2}{c}{ Trisha in Course \#7 } \\
& \multicolumn{2}{c}{$\begin{array}{c}\text { Course } \\
\text { Mean (SD) }\end{array}$} & $\begin{array}{c}\text { Course } \\
\text { Trisha }\end{array}$ & $\begin{array}{c}\text { Course } \\
\text { Mean (SD) }\end{array}$ & $\begin{array}{c}\text { Trisha } \\
\text { Mean (SD) }\end{array}$ \\
\hline Time Online (Hours) & 77 & $74(36)$ & 63 & $61(20)$ & 64 & $61(28)$ \\
Sessions & 89 & $247(136)$ & 152 & $164(94)$ & 149 & $152(114)$ \\
Days Online & 58 & $94(31)$ & 85 & $70(26)$ & 80 & $62(34)$ \\
Likes Given & 34 & $54(42)$ & 79 & $47(39)$ & 181 & $65(71)$ \\
Likes Received & 20 & $50(30)$ & 85 & $46(28)$ & 146 & $61(38)$ \\
Entries Written & 39 & $74(39)$ & 198 & $87(50)$ & 190 & $86(46)$ \\
Words Written & 11512 & $20679(13053)$ & 15998 & $14196(6624)$ & 16021 & $12940(8503)$ \\
Replies to other entries & 34 & $64(38)$ & 172 & $76(47)$ & 180 & $72(43)$ \\
Replies Received & 10 & $60(34)$ & 138 & $73(43)$ & 139 & $73(38)$ \\
Entries Read & 571 & $982(384)$ & 1124 & $963(426)$ & 1481 & $1274(570)$ \\
\hline
\end{tabular}

Course \#3 had Total Student Entries of 1112 and Total Teacher Entries of 182, with 15 Students

Course \#5 had Total Student Entries of 1485 and Total Teacher Entries of 197, with 17 Students

Course \#7 had Total Student Entries of 2067 and Total Teacher Entries of 238, with 24 Students

In addition to the participants' activities in each course, Table 5 provides a summary of the average course activities. The courses had different levels of activity. For example, the average time spent online by participants in course 3 (74 hours) was higher than those in course 5 (61 hours) and course 7 (61 hours). In context, Samira spent more time online in her course (77 hours) than average. Compared to each other, Trisha logged into her courses (152 and 149 times) far more often than Samira (89 times). As well, Samira posted 39 entries with an average of 295 words in each, whereas Trisha posted 198 and 190 entries, with lower averages of 81 and 84 words in each course. 
Samira and Trisha explained, during in-depth interviews, how rereading contributed to their learning. Their comments fit into six themes:

Re-reading in order to participate in the discussion (for social purposes)

Re-reading to apply to future learning

Re-reading in order to achieve a deeper understanding

Re-reading to find models/understand course/participation expectations

Re-reading in the role of weekly moderator

Re-reading for resources

In the interest of space limitations, the following two themes will be discussed: Rereading in order to achieve a deeper understanding, and rereading to find models/understand course/participation expectations.

Samira explains that it is important to re-read student comments "to just get a sense of their contributions and again to understand, make sure that I fully understand the points they've made... so that I'm not misunderstanding or misconstruing anything." This is important to her as she explains that "then maybe I could build on a previous point or comment on another student's ideas and then build on those." As well, timing affected Samira's revisiting activities. She explains,

In an online environment, students are contributing at different times. And so, if I have read up to a certain point, and then I come back and other students have contributed to that original post, I want to make sure that I have read the original post, or revisited it, so that I can see the connections or linkages with the new post, or comments that have been made to the original point.

Trisha commented on the value of peer posts, that "the idea of distributed cognition comes to mind and that each individual brings something to the conversation." As she extends her understanding through rereading, she explains that

I find if I go back to reread a post... it is usually for one of two reasons. If a post really stood out to me and I want to build upon it, I will go back to reread so I can use a particular quote, example, or line. I may also reread/revisit a post if I want to challenge it. I may also revisit other posts to bring into my argument. We tend to skim and scan digital texts, which I find plays a HUGE part in reading online. It takes time to step back and not treat an online environment as we would social media or email. You almost have to immerse yourself in the environment.

Overall, the case study data show interesting differences in how students approach online courses and give insight into the motivation behind their various online activities. Trisha reread more complex and subtle entries that pose teaching challenges or that question orthodoxy about teaching - most entries are questioning what the nature of learning really is and what kinds of experiences teachers might provide for students in the classrooms that truly engage them as learners. Samira, by contrast, tended to revisit lengthy, content-heavy, summary documents about concepts that contained links and further references. 


\section{Discussion}

Overall, these findings indicate that those who are less visible in online learning discussions are actively learning through reading, rereading, and revisiting entries. Clustering the groups into categories of reading and writing behaviors identified significant differences in time online and rereading behaviors. The less visible participants in this study were still actively involved in the non-posting activities of reading and rereading. In fact, the data showed that the Moderate Readers/Moderate Writers were more likely, on average, to revisit teacher entries in higher proportion to revisiting other student entries than the two other groups. These findings align with Yang \& Richardson's (2008) observations of online learning approaches, Sutton's (2001) identification of vicarious interactions, and Creelman's (2017) proposal of students' learning perspectives.

The online survey interview participants, representing all three clusters, agreed that rereading student entries contributed to deepening understanding. The Moderate Reader/Writer participants felt that composing an entry with an opinion that has not been expressed by others and composing an entry that refers to another student's entry were very important. To compose these types of entries, other student entries must be read and possibly reread. This may explain that these types of participants spend more time in non-posting activities but are still actively engaged. All groups felt that Revisiting students' entries to improve my understanding was important, with the Moderate Readers/Writers agreeing most strongly with that statement. The results suggest that those who read a lot did not do so because they believed that reading every entry was an expectation. This data supports the notion that students find reading other entries important to learning and, unlike posting an entry because it is expected and may affect their grade, as suggested by Dennen (2008) and Ho and Swan (2007), they do not read or reread in order to meet instructor expectations. In addition, one respondent who was less visible explained in her interview that she was very thoughtful when crafting her responses. She would spend time composing and commented, "I would try to make my contributions as clear as possible, because in written format, sometimes things could be misunderstood." It seems that some students will take more time than others to respond if they prefer to read and reread what others have said before carefully composing an entry. Creelman's (2017) proposal that silent participants may be unclear about the rules or etiquette of online participation, may need more time to think before contributing, or whose behavior may be influenced by their prior cultural experiences in learning environments, are supported by these findings.

Confirming earlier findings in Wise et al.'s $(2012 ; 2013 a ; 2013 b)$ studies, these data suggest that revisiting supports student learning and illustrates the value of using a microanalytictype exploration to contribute a more nuanced understanding of the different roles revisiting plays in the learning of different participants. For example, the kinds of lengthy and complex entries Samira revisited may indicate in part where she spent her more extensive time online. By deeply examining individual student activities, the relationship of non-posting activities to deepening understanding has been highlighted. Trisha describes rereading as a way to extend her own understanding beyond the course content and particularly to connect her learning with her professional teaching role. For Samira, rereading entries seemed to support extending her own understanding of course content and facilitate productive discussion contributions. Instructionally, this important feedback may encourage the valuing of different "paths" to online learning success beyond the criterion of written entries as suggested by Goodfellow (2004), Sutton (2001) and Yang and Richardson (2008). 
Participants identified a few consistent features in the types of entries they preferred to revisit. Students revisited other student's entries to find resources, to seek a deeper understanding, to clarify or build on their understandings, or to engage with examples, questions, or thoughtprovoking content. Respondents indicated that they preferred to revisit well-written responses. In looking specifically at rereading, revisiting could be considered a social practice that does not have an equivalent practice in face-to-face discussions, as suggested by Knobel (2015). The permanence of the discussion offers affordances not generally available in a classroom. Students adopt the replaying of these online conversations for many reasons including to clarify, to build on their understanding, and to support a socially correct response. Participants reported revisiting long after the course was over to continue to learn. This pattern of behavior is less examined but adds to the patterns observed by Vogler et al. (2013). It is important to note that while students may sometimes engage in online activities simply for marks, revisiting after the course is over is most likely linked to the participant's desire to learn. These responses support the notion that revisiting is an important social practice when participating in a DBOLE.

It appears that the participants who are less visible in a DBOLE care about their interactions with others. Although they write less than others, they appear to attribute a higher level of importance to interaction with others than their more visible student colleagues. This finding indicates that it could be misleading to say that this group is less engaged than others. They simply adopt different social practices, as suggested by Lankshear and Knobel (2004) than those who are more visible.

One limitation of the study is that it took place in a unique online learning environment different from other online learning environments that may not offer the capability to look for detailed data on entry openings. Additionally, the sample of respondents participating in the online survey and interviews was small, and the study was undertaken in courses taught by a very skilled instructor who purposely facilitated rich discussions. Moreover, the students were studying in the field of education, so they may have had a heightened awareness of measured contributions. The findings cannot be generalized beyond the investigated case. However, Blatter (2008) suggests "The findings can be taken up by others if they perceive a 'fit' to their cases" (p. 69).

\section{Conclusions}

Instructional design implications could suggest the development or inclusion of tools which report on reading and revisiting activities. It may be possible to highlight entries that are highly reread by both the instructor and the students so that the students might benefit from the contents of the highly reread entries too. Including a feature that allows students to bookmark entries they find important to their learning may also be warranted in order to facilitate further revisiting.

Pedagogical decisions may be influenced by these findings as well. Less visible learners may need to be evaluated using methods that are different from those used to evaluate visible learners on the basis of quantity of entries. Learning and instructional practices might usefully be informed by monitoring evolving social practices in online contexts that are yet to be identified or understood. Further studies that contribute to establishing a framework for understanding social practices may uncover patterns related to less visible participants' activities and help to deepen our perspectives of approaches to learning in a DBOLE. Further research on these non-posting 
activities is important to deepening our understanding of the ways students learn in this digital context.

Future studies could be broadened to examine data from the perspectives of the psychology of reading (Baker \& Brown, 1984; Pressley, et al., 1992) or to consider the implications from Coiro's (2014) research on online reading. This study's goals of examining learners' patterns of writing, reading, and rereading in eight DBOLEs has served to highlight the non-posting activities that are taking place in these learning environments. The respondents felt these activities, both visible and non-visible, were important to their learning experiences. It is important to reconsider how quiet participants can best be supported in the rapidly expanding world of discussion-based learning. 


\section{References}

Baker, L., \& Brown, A. L. (1984) Metacognitive skills and reading. Handbook of reading research, 1(353), V394.

Barbour, M. K., \& LaBonte, R. (2017). State of the nation: K-12 e-learning in Canada, 2017 Ed. Retrieved from http://k12sotn.ca/wp-content/uploads/2018/02/StateNation17.pdf

Bhattacharya, H. (2008). Interpretive research. In Lisa M. Given (Ed.), The Sage encyclopedia of qualitative research methods (pp. 465-468). Thousand Oaks, CA: Sage Publications.

Blatter, J. K. (2008). Case study. In Lisa M. Given (Ed.), The Sage encyclopedia of qualitative research methods (pp. 68-71). Thousand Oaks, CA: Sage Publications.

Bonk, C. J., \& Cunningham, D. J. (1998). Searching for learner-centered, constructivist, and sociocultural components of collaborative educational learning tools. In C. J. Bonk \& K. S. King (Eds.), Electronic collaborators: Learner-centered technologies for literacy, apprenticeship and discourse (pp. 25-50). Mahwah, NJ: Erlbaum.

Coiro, J. (2014). Online Reading Comprehension: Challenges and Opportunities. Texto Livre: Linguagem e Tecnologia, 7(2), 30-43. Retrieved from http://dx.doi.org/ 10.17851/1983-3652.7.2.30-43

Creelman, A. (2017). NVL: Silent learners-a guide. Retrieved from http://lnu.divaportal.org/smash/get/diva2:1171709/FULLTEXT01.pdf

Creswell, J. W., \& Plano Clark, V. L. (2011). Designing and conducting mixed methods research (2nd ed.). Thousand Oaks, CA: Sage Publications.

Creswell, J. W. (2013). Qualitative inquiry and research design: Choosing among five approaches (3rd ed.). Thousand Oaks, CA: Sage Publications.

Dennen, V. P. (2006). Shaping learners' online dialogues: The role of discourse models. Technology, Instruction, Cognition and Learning, 3, 249-264.

Dennen, V. P. (2008). Looking for evidence of learning: Assessment and analysis methods for online discourse. Computers in Human Behavior, 24, 205-219.

Dennen, V. P., \& Wieland, K. (2007). From interaction to intersubjectivity: Facilitating online group discourse processes. Distance Education, 28(3), 281-297. Retrieved from http://dx.doi.org/10.1080/01587910701611328

Ebner, M., \& Holzinger, A. (2005). Lurking: An underestimated human-computer phenomenon. IEEE, 12(4), 70-75. doi 10.1109/MMUL.2005.74

Goodfellow, R. (2004). Online literacies and learning: Operational, cultural and critical dimensions. Language and Education, 18(4), 379-399.

Green, S. B., \& Salkind, N. J. (2011). Using SPSS for Windows and Macintosh: Analyzing and understanding data. Upper Saddle River, NJ: Prentice Hall.

Guba, E. G., \& Lincoln, Y. S. (1994). Competing paradigms in qualitative research. In N. K. Denzin, \& Y. S. Lincoln (Eds.), Handbook of qualitative research (pp. 105-117). Thousand Oaks, CA: Sage

Harasim, L. (2012). Learning theory and online technologies. New York, NY: Routledge.

Ho, C. H., \& Swan, K. (2007). Evaluating online conversation in an asynchronous learning environment: An application of Grice's cooperative principle. Internet and Higher Education, 10, 3-14.

Hrastinski, S. (2008). What is online participation? A literature review. Computers \& Education, 51, $1755-1765$. 
Hrastinski, S. (2009). A theory of online learning as online participation. Computers \& Education, 52, 7882.

John-Steiner, V., \& Souberman, E. (1978). Afterword. In M. Cole, V. John-Steiner, S. Scribner, \& E. Souberman (Eds.), Mind in society: the development of higher psychological processes. Cambridge, MA: Harvard University.

Johnson, L., Adams Becker, S., Cummins, M., Estrada, V., Freeman, A., \& Ludgate, H. (2014). NMC horizon report: 2014 K-12 Ed. Austin, Texas: The New Media Consortium. Available at http://cdn.nmc.org/media/2014-nmc-horizon-report-k12-EN.pdf

Knobel, M. (2015, Dec. 3). Personal conversation at Literacy Research Association Conference, Carlsbad, CA.

Knobel, M., \& Lankshear, C. (2015, June 3). Researching and understanding new literacies from a social languages perspective. Opening keynote paper presented at the Futuuri! Language Summer School and the Language Centre Conference, Jyvaskyla, Finland. Retrieved from http://www.academia.edu/12829531/Researching_and_Understanding New_Literacies_from_a_Social_Languages_Perspective

Kvale, S. (2007). Analyzing interviews. In S. Kvale (Ed.), Doing Interviews (pp. 102-120). London, England: Sage Publications. Retrieved from http://dx.doi.org/10.4135/9781849208963.n9

Lankshear, C., \& Knobel, M. (2004, Dec. 2). "New” literacies: Research and social practice. Plenary address at the Annual Meeting of the National Reading Conference, San Antonio, TX. Retrieved from http://everydayliteracies.net/files/nrc.html

Lankshear, C., \& Knobel, M. (2007). Sampling "the new in new literacies.” In M. Knobel \& C. Lankshear (Eds.), A new literacies sampler (pp. 1-24). New York, NY: Peter Lang.

Lave, J., \& Wenger, E. (1991). Situated learning: Legitimate peripheral participation. Cambridge: Cambridge University Press.

Means, B., Toyama, Y., Murphy, R., Bakia, M., \& Jones, K. (2010, Sept.). Evaluation of evidence-based practices in online learning: A meta-analysis and review of online learning studies. Washington, DC: U.S. Department of Education. Retrieved from http://www2.ed.gov/rschstat/eval/tech/evidence-based-practices/finalreport.pdf

Nagel, L., Blignaut, A. S., \& Cronjé, J. C. (2009). Read-only participants: A case for student communication in online classes. Interactive Learning Environments, 17(1), 37-51.

Nonnecke, B. \& Preece, J. (2003). Chapter 6: Silent participants: Getting to know lurkers better. In C. Lueg, \& D. Fisher (Eds.) From Usenet to CoWebs: Computer Supported Cooperative Work, pp. 110-132).

Perkins, J., \& Newman, K. (1996). Two archetypes in e-discourse: Lurkers and virtuosos. International Journal of Educational Telecommunications, 2, 155-170.

Peters, V. L., \& Hewitt, J. (2010). An investigation of student practices in asynchronous computer conferencing courses. Computers \& Education, 54(4), 951-961.

Picciano, A. G. (2016). Paradigms, methodologies, methods, and the role of theory in online and blended learning research. In C. D. Dziuban, A. G. Picciano, C. R. Graham, \& P. D. Moskal (Eds.), Conducting research in online and blended learning environments: New pedagogical frontiers (pp. 12-27). New York, NY: Routledge.

Pressley, M, El-Dinary, P. B., Gaskings, I., Schuder, T., Bergmain, J. L., Almasi, J., \& Brown, R. (1992) Beyond direct explanation: Transactional instruction of reading comprehension strategies. The Elementary School Journal, 92(5), 513-555. 
Rourke, L., \& Kanuka, H. (2009). Learning in communities of inquiry: A review of the literature. Journal of Distance Education, 23(1), 19-48. Retrieved from http://www.jofde.ca/ index.php/jde/article/view/474/815

Rovai, A. P. (2000). Building and sustaining community in asynchronous learning networks. The Internet and Higher Education, 3, 285-297.

Sipe, L., \& Constable, S. (1996). A chart of four contemporary research paradigms: Metaphors for the modes of inquiry. Taboo: The Journal of Culture and Education, 153-163.

Sutton, L. (2001). The principle of vicarious interaction in computer mediated communications. International Journal of Educational Telecommunications, 7(3), 223-242.

Swan, K., Shen, J., \& Hiltz, S. R. (2006). Assessment and collaboration in online learning. Journal of Asynchronous Learning Networks, 10(1), 45-62.

Vogler, J. S., Schallert, D. L., Park, Y., Song, K., Chiang, Y. V., Jordan, M. E., Lee, S., Cheng, A. J., Lee, J., Park, J., \& Sanders, A. J. Z. (2013). A microgenetic analysis of classroom discussion practices: How literacy processes intermingle in the negotiation of meaning in an online discussion. Journal of Literacy Research, 45(3), 211-239. Retrieved from http://dx.doi.org/10.1177/1086296X13499846

Vygotsky, L. (1986). Thought and language. Cambridge, MA: The MIT Press.

Wilton, L. (2017). The three Rs of online learning: Interpretive views of the social practices of reading, rereading, and revisiting. Doctoral Dissertation, University of Toronto.

Wilton, L., \& Brett, C. (April 2015). Broadening our conceptions of online engagement: adding to the conventional measures. In Proceedings of American Educational Research Association (AERA) Conference. Chicago, ILWise, A. F., Perera, N., Hsiao, Y., Speer, J., \& Marbouti, F. (2012). Microanalytic case studies of individual participation patterns in an asynchronous online discussion in an undergraduate blended course. The Internet and Higher Education, 15(2), 108117.

Wise, A. F., Hausknecht, S., \& Zhao, Y. (2013a). Relationships between listening and speaking in online discussions: An empirical investigation. In N. Rummel, M. Kapur, M. Nathan, \& S. Puntambekar (Eds.) Proceedings of the 10th International Conference on Computer Supported Collaborative Learning, Vol I (pp. 534-541). Madison, WI.

Wise. A. F., Speer, J., Marbouti, F., \& Hsiao, Y. T. (2013b). Broadening the notion of participation in online discussions: Examining patterns in learners' online listening behaviors. Instructional Science, 41(2), 323-343.

Yang, D., \& Richardson, J. (2008). Students' online interaction styles: Can they change? Journal of Educational Technology Development and Exchange, 1(1).

Yin, R. K. (2014). Case study research: Design and methods, (5 ${ }^{\text {th }}$ ed.). Thousand Oaks, CA: Sage Publications. 


\section{Appendix A: Portion of Online Questionnaire Addressing Social Practices, Activities and Behaviors Related to Reading, Revisiting, and Rereading in a DBOLE.}

1. My opinion of online learning is ...

1. Very unfavourable

2. Somewhat unfavourable

3. Neither

4. Somewhat favourable

5. Very favourable

2. How many fully online courses have you completed?
0. Zero
1. One
2. Two
3. Three
4. Four
5. Five
6. Six or more

3. In thinking of online learning discussions that require students to express their thoughts to others and to understand others' expressed thoughts, rate your level of confidence in using the English language in such an environment.

1. Not confident at all

2. Not very confident

3. Neither confident nor not confident

4. Somewhat confident

5. Very confident 
4. Please rate the importance of the following skills or abilities to successful online learning using the scale below giving a rating from $1-5$, where 1 is not important at all and 5 is very important.

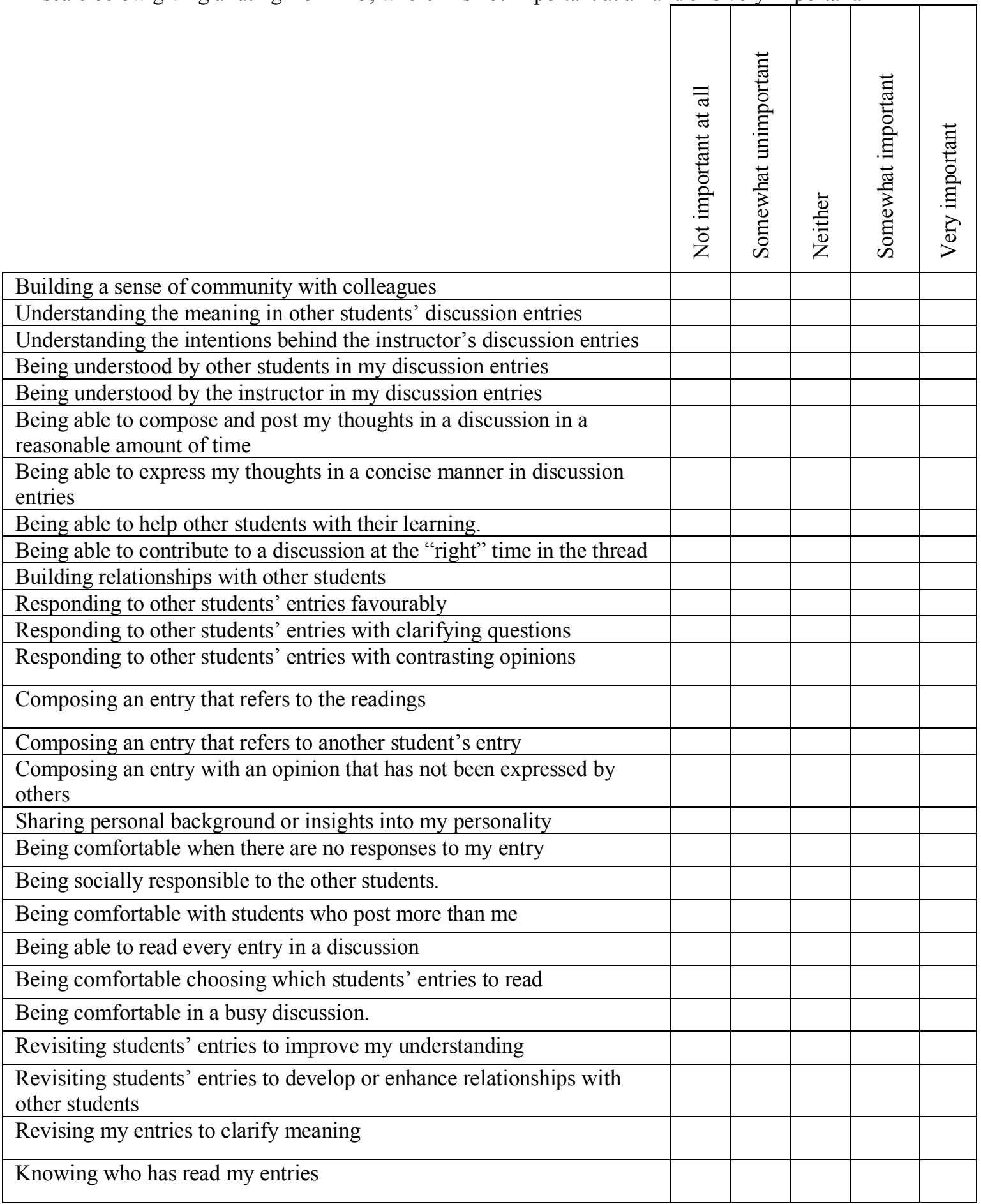

5. As if explaining the online learning discussion environment to an experienced student, please describe up to three of the most important skills or abilities needed to be successful. (open-ended) 
6. In your first fully online course, at what point did you feel you understood or felt comfortable with the following:

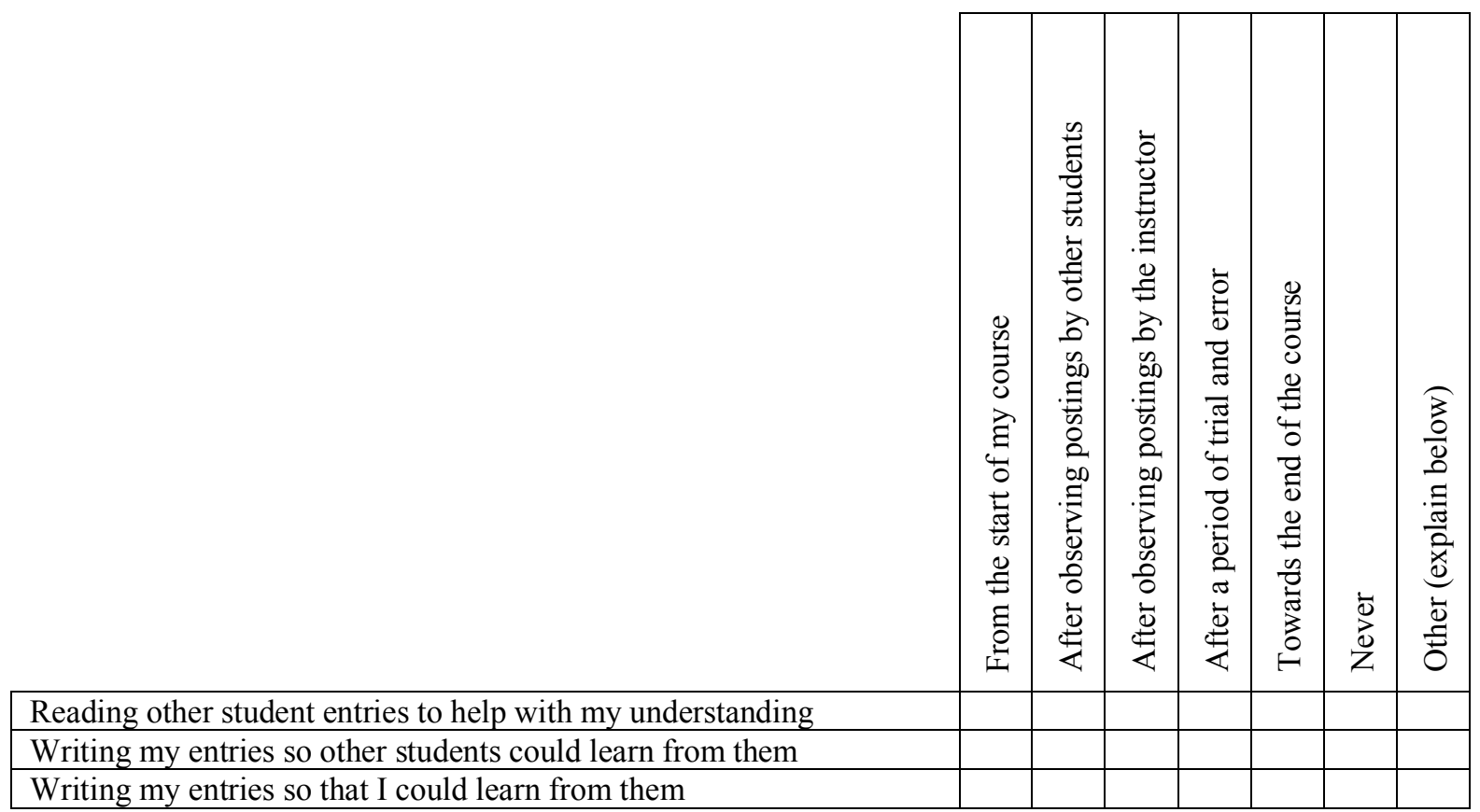

If you selected other, please explain.

7. Did you find it helpful to know who had read your notes?

1. Yes

2. No

3. I did not know about this option but would have found it helpful

4. I did not know about this option but would not have found it helpful

8. Have you opened another student's note to purposely reread it?

1. Yes

2. No

9. Please describe briefly your primary reasons for revisiting/rereading previously read entries created by other students.

10. Please select all the reasons you may have revisited previously read entries created by other students.

1. It looked like a new posting, but I had read an earlier version

2. It added a perspective on something I was having difficulty with

3. It was helpful to my learning

4. It contained resources that I found helpful

5. I was partnered with a student and had to read their entries

6. It was important in order to fit it.

7. It was important to remember details about other students

8. I was notified that a link to one of my entries was in a posting

9. In order to provide a link to one of my posts 
10. To find a model for something I was trying to do

11. Other (please explain below)

11a. Other-please explain

11. Please describe the types of student-generated notes that you would likely reread/revisit.

12. Please add any information, based on your own experience that may help us to further understand the importance of revisiting or rereading notes to online learning.

13. In terms of design of the learning environment, would you find it valuable if you were able to see which of your notes were reread/revisited by other students?

1. Yes

2. No

14. In terms of design of the learning environment, would you find it valuable if you were able to see which student-generated notes are the most highly reread/revisited?

1. Yes

2. No

(Wilton, 2017) 


\section{Appendix B: Portion of Semi-Structured Interview Questions Addressing Social Practices, Activities and Behaviors Related to Reading, Revisiting, and Rereading in a DBOLE.}

Briefly describe your experience with online learning discussion environments.

1. In thinking of discussion expectations in your first online learning environment, how did you know what behaviors were expected in those discussions?

2. Please describe any literacy practices you think are important to an online learning discussion environment?

3. How important is reading other students' entries to your learning? (Please describe.)

4. Can you think of a time when you may have felt uncomfortable learning by reading other students' thoughts? (Please describe.)

(Wilton, 2017) 